\title{
Seasonal variations in the body composition of lightweight rowers
}

Department of Medicine, University of Melbourne F L Morris

School of Human Movement and Sport Sciences, University of Ballarat

W R Payne

Correspondence to: Fiona L Morris, Department of Medicine, University of Melbourne/Royal Melbourne Hospital, Royal Parade, Parkville, Victoria 3052, Australia.

Accepted for publication 14 March 1996

\begin{abstract}
Objective-To monitor the seasonal body composition alterations in 18 lightweight rowers (six females, 12 males) across a rowing season incorporating preseason, early competition, competition, and postseason.

Methods-Subject age was 23.1 (SD 4.5) years, height $170.8(5.6) \mathrm{cm}$ (female), 23.5 (3.5) years, 180.5 (2.7) cm (male). Body weight, fat mass, and fat-free mass (FFM) were assessed using dual energy $x$ ray absorptiometry (DXA-L Lunar) and skinfold techniques. Weight control techniques were documented before major regattas by a questionnaire.

Results-Female body weight was reduced from $61.3(2.9)$ to $57.0(1.1) \mathrm{kg}(5.9 \%)$, while male body weight was reduced from $75.6(3.1)$ to $69.8(1.6) \mathrm{kg}(7.8 \%)$ preseason to competition season respectively. These body weight reductions were mirrored by a significant reduction in fat mass as indicated by the sum of skinfolds [female seven sites: 80.9 ( 8.1) to $68.2(11.8) \mathrm{mm}$; male eight sites: $54.2(8.7)$ to $41.8(4.8)$ $\mathrm{mm}$ ], percentage body fat [female 22.1 (1.0) to $19.7(2.4) \%$; male $10.0(0.9)$ to 7.8 (0.8) \%], and total fat [female 12.5 (5.2) to 10.9 (1.4) kg; male $7.3(1.9)$ to $5.6(1.8) \mathrm{kg}]$ (DXA). In contrast, no changes were observed in FFM despite a season of intensive rowing training. Seasonal body weight control was achieved through reduced total energy and dietary fat intakes. Acute body weight reductions were achieved by exercise in $73.3 \%$ of participants, food restriction in $71.4 \%$, and fluid restrictions in $62.9 \%$.

Conclusions-Seasonal body weight alterations in lightweight rowers are in response to a significant reduction in fat mass. However, the weight restrictions appear to be limiting an increase in FFM which could be beneficial to rowing performance.

(Br F Sports Med 1996;30:301-304)
\end{abstract}

Key terms: weight reduction; dual energy $x$ ray absorptiometry; fat mass; fat-free mass

Lightweight rowing specifies that male competitors weigh no more than $72.5 \mathrm{~kg}$, with a crew average of $70.0 \mathrm{~kg}$, and female competitors weigh no more than $59.0 \mathrm{~kg}$, with a crew average of $56.7 \mathrm{~kg}$. ${ }^{1}$ To meet these criteria, the lightweight rowers typically reduce their body weight during competition season and regain this weight during the off-season. ${ }^{2}$ Little information has been published regarding the effects of the seasonal body weight fluctuations on body composition experienced by lightweight rowers, specifically fat and lean mass.

Longer term weight fluctuations throughout the season are typically achieved through restricted food consumption and intense exercise. $^{2}$ In contrast, in many weight limited sports, acute weight loss before competition is achieved by energy restriction, along with various dehydration techniques such as excessive exercise, plastic wraps, saunas, induced vomiting, laxatives, diuretics, and sweat runs. ${ }^{3}$ Despite documentation of the detrimental impact that these weight loss techniques have on rowing performance, ${ }^{4}$ use of the techniques persists.

Most controlled studies have reported a significant loss of lean body mass associated with energy restrictions. ${ }^{5}$ However, when energy restrictions were supplemented by exercise, the physical activity provided the necessary stimulus for the maintenance of muscle mass. ${ }^{5}$ Body composition alterations in athletes, associated with training, has indicated a trend towards a reduction in fat mass, with a small to moderate increase in lean mass. ${ }^{6}$ However, this body composition trend may not be apparent in weight restricted athletes.

The purpose of our study was therefore twofold: (1) to document the weight loss techniques employed throughout the rowing season; and (2) to evaluate the effect of energy restrictions on the body composition of the lightweight rower and assess whether the incorporation of intense training provides the necessary stimulus to maintain or increase lean tissue.

\section{Methods}

Subjects were 18 lightweight rowers (six female, 12 male), aiming for a Victorian Institute of Sport rowing scholarship and possibly Australian team selection. Unfortunately, the female lightweight rowers missed one competition assessment because of their unwillingness to be involved in the study at this stage of the season. The mean age of the female lightweight rowers at the start of the study was 23.1 (SD 4.5) years, height $170.8(5.6) \mathrm{cm}$, and weight $61.3(2.9) \mathrm{kg}$. The mean age for the male lightweight rowers was 23.5 (3.5) years, height $180.5(2.7) \mathrm{cm}$, and weight 75.6 (3.1) kg. Race weight for the female and male lightweight rowers was $57.0(1.1)$ and $69.8(1.6) \mathrm{kg}$, respectively. The subjects were instructed to 
Table 1 Nutritional consumption of total kilojoules, carbohydrate, protein and fat ( $\left(d^{-1}\right)(\%)$ for female and male lightweight rowers, over a rowing season. Values are mean (SEM) or mean (\%)

\begin{tabular}{|c|c|c|c|c|c|}
\hline & Preseason & Early comp & Competition & Postseason & \\
\hline $\begin{array}{l}\text { Females }(\mathrm{n}=6) \\
\text { Energy }(\mathrm{kJ}) \\
\text { Carbohydrate }\left(\mathrm{g} \mathrm{d}^{-1}\right) \\
\text { Protein }\left(\mathrm{g} \mathrm{d}^{-1}\right) \\
\text { Fat }\left(\mathrm{g} \mathrm{d}^{-1}\right)\end{array}$ & $\begin{array}{c}6864(2188) \\
260(58 \%) \\
73(17 \%) \\
48(21 \%)\end{array}$ & $\begin{array}{c}5033(2542)^{\mathrm{a}} \\
208(63 \%) \\
48(16 \%) \\
34(22 \%)\end{array}$ & $\begin{array}{c}4972(2133)^{\mathrm{b}} \\
214(68 \%) \\
37(15 \%)^{\mathrm{b}} \\
32(15 \%)^{\mathrm{b}}\end{array}$ & $\begin{array}{c}8660(3661) \\
283(52 \%) \\
90(18 \%) \\
73(31 \%)^{c}\end{array}$ & $\begin{array}{r}\text { * } \\
\text { * } \\
\text { * }\end{array}$ \\
\hline $\begin{array}{l}\text { Males }(\mathrm{n}=12) \\
\text { Energy (kJ) } \\
\text { Carbohydrate }\left(\mathrm{g} \mathrm{d}^{-1}\right) \\
\text { Protein }\left(\mathrm{g} \mathrm{d}^{-1}\right) \\
\text { Fat }\left(\mathrm{g} \mathrm{d}^{-1}\right)\end{array}$ & $\begin{array}{c}10997(2240) \\
354(52 \%) \\
98(15 \%) \\
86(28 \%)\end{array}$ & $\begin{array}{c}9657(2870) \\
427(65 \%) \\
98(19 \%) \\
37(21 \%)^{\mathrm{a}}\end{array}$ & $\begin{array}{c}9795(4899) \\
415(67 \%) \\
100(18 \%) \\
33(14 \%)^{\mathrm{b}}\end{array}$ & $\begin{array}{c}12699(5275) \\
354(46 \%) \\
118(16 \%) \\
113(34 \%)\end{array}$ & $\begin{array}{l}\text { NS } \\
\text { NS } \\
\text { NS } \\
\star\end{array}$ \\
\hline
\end{tabular}

MANOVA: Main effect across time, ${ }^{\star} \mathrm{P}<0.05$.

TUKEY post-hoc: Comparison between pre-season and early competition, ${ }^{\mathrm{a}} \mathrm{P}<0.05$, comparison between pre-season and competition, ${ }^{\mathrm{b}} \mathrm{P}<0.05$, comparison between pre-season and post-season, ${ }^{\mathrm{c}} \mathrm{P}<0.05$.

follow their normal training and competition programme and participate in their usual weight loss and dietary habits to ensure behaviour was as consistent as possible. Body composition estimates were made preseason in October, twice during the competition season (state and national championships), and postseason in July. Procedures were approved by the University of Ballarat human experimentation ethics committee.

A questionnaire was employed to document the two aspects of weight management; long term seasonal and short term weight control practices. The questions were closed ended in order to facilitate the administration of the questionnaire and subsequent data analysis. No personal information was requested in order to maintain anonymity. The lightweight rowers responded to three questions: the first documented their seasonal body weight fluctuations during preseason, competition season, race day, and postseason; the second documented long term weight loss strategies; and the third documented the acute weight loss methods employed over the final seven days leading up to competition day. Criterion validity for certain questions was determined by making comparisons with race weigh-in records and body weight obtained from dual energy $x$ ray absorptiometry (DXA) scans. The limitations of self report are acknowledged.

All subjects completed a four day nutritional intake record, comprised of three mid-week days and one weekend day, during the two weeks leading into the testing period. This information was analysed using the NUTAB dietary analysis program (Diet 3). A full analysis of the nutritional consumption is presented in a separate publication.

Anthropometric measurements of height, weight, and sum of seven/eight skinfolds were

Table 2 Change in body fat levels for female and male lightweight rowers over a rowing season. Values are mean (SEM).

\begin{tabular}{|c|c|c|c|c|c|}
\hline Technique & Preseason & Early comp & Competition & Postseason & \\
\hline $\begin{array}{l}\text { Females }(\mathrm{n}=6) \\
\text { Withers \% fat } \\
\text { Skinfold total }\end{array}$ & $\begin{array}{l}22.14(0.5) \\
80.9(8.1)\end{array}$ & $\begin{array}{l}19.68(1.0)^{\mathrm{a}} \\
68.2(11.8)^{\mathrm{a}}\end{array}$ & - & $\begin{array}{l}23.40(0.8) \\
84.8(9.2)\end{array}$ & * \\
\hline $\begin{array}{l}\text { Males }(n=12) \\
\text { Withers \% fat } \\
\text { Skinfold total }\end{array}$ & $\begin{array}{l}10.02(0.9) \\
54.2(8.7)\end{array}$ & $\begin{array}{r}7.82(0.8)^{\mathrm{a}} \\
41.8(4.8)^{\mathrm{a}}\end{array}$ & $\begin{array}{r}8.31(0.7)^{\mathrm{b}} \\
42.3(4.4)^{\mathrm{b}}\end{array}$ & $\begin{array}{l}10.80(1.4) \\
58.7(7.8)\end{array}$ & * \\
\hline
\end{tabular}

MANOVA: Main effect across time, ${ }^{\star} \mathrm{P}<0.05$.

TUKEY post-hoc: Comparison between pre-season and early competition, ${ }^{\mathrm{a}} \mathrm{P}<0.05$, comparison between pre-season and competition, ${ }^{\mathrm{b}} \mathrm{P}<0.05$.

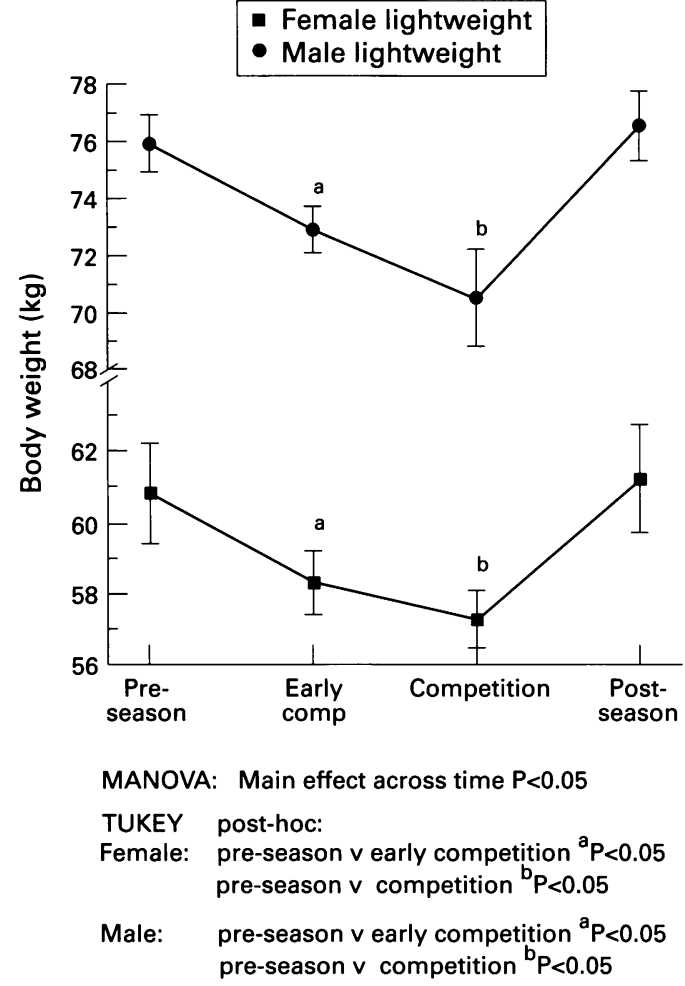

Figure 1 Seasonal comparison of body weight of female $(n=6)$ and male $(n=12)$ lightweight rowers as measured by dual energy $x$ ray absorptiometry $(D X A)$. Values are means, bars $=$ SEM $(\mathrm{kg})$.

recorded from all subjects and were consistent with the guidelines of the International Society for the Advancement of Kinanthropometry (ISAK). All measurements were made by the same person to ensure consistency in results. To estimate percent body fat from anthropometric measurements, the Withers ${ }^{78}$ multiple regression equation was used to determine body density $\left(\mathrm{g} \mathrm{cm}^{-3}\right)$. The Siri equation ${ }^{9}$ was then employed to calculate the percent fat from body density. The DXA technique was used to assess body composition and bone mass (DPX-L Lunar Radiation, Madison, WI, USA). Each subject underwent a whole body scan, involving a 12 minute scan time. A low dose $x$ ray was emitted, based on differential attenuations of two photon energies of 38 and $70 \mathrm{keV}$ transversing a medium consisting of predominantly soft tissue and bone. The ratio of fat to fat-free mass was determined by measuring the attenuation for each photon energy in 


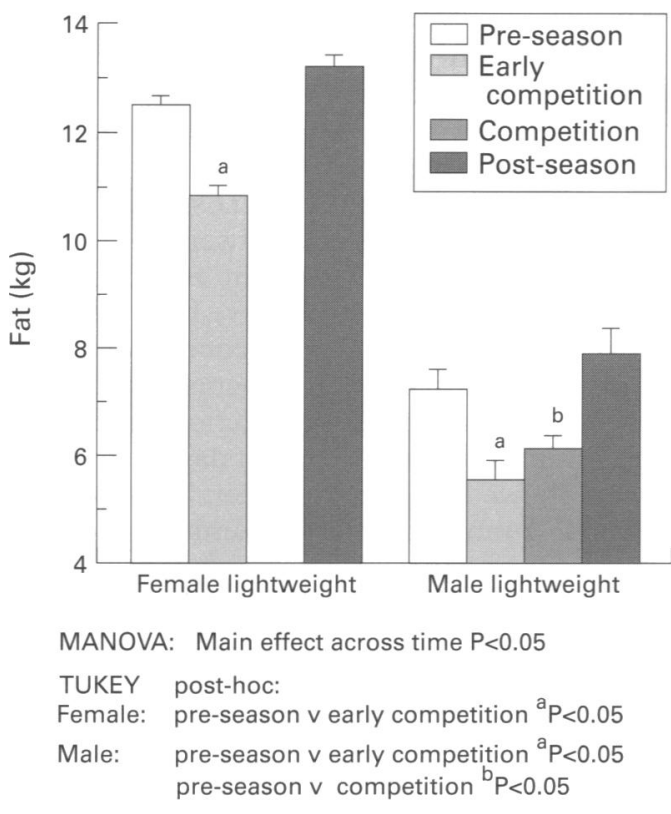

Figure 2 Seasonal comparison of body fat estimate $(\mathrm{kg})$ of female $(n=6)$ and male $(n=12)$ lightweight rowers, as measured by dual energy $x$ ray absorptiometry (DXA).

Values are means, error bars $=$ SEM.

soft tissue. The reported coefficient of variation for the machine was $1.5 \%$ for fat-free mass. ${ }^{10}$

STATISTICS

The data were analysed using the SPSS 6.0 for Windows statistical software. Where appropriate, data were analysed using analysis of variance (ANOVA) to examine body composition variables across time. Significant interaction effects were examined using Tukey post-hoc analysis. Statistical significance was set at the 0.05 level of confidence.

\section{Results}

Examination of the female and male lightweight rowers' body weight across the season revealed significant reductions at competition season to a seasonal low of $57.0 \mathrm{~kg}$ (female) and $69.8 \mathrm{~kg}$ (male), equating to a $5.9 \%$ seasonal body weight decrease in the female rowers and $7.8 \%$ in the male rowers. Postseason, the body weight lost for competition was regained (fig 1). Seasonal body weight reductions were attributed, in part, to dietary restrictions, and more specifically to significant reductions in total energy $(\mathrm{kJ})$, absolute protein $\left(\mathrm{g} \mathrm{d}^{-1}\right)$ and absolute fat consumption $\left(\mathrm{g} \mathrm{d}^{-1}\right)$ (table 1)

The average body weight loss of the female and male lightweight rowers over the final seven days leading up to the National Championship regatta was $2.8 \mathrm{~kg}(4.7 \%)$ and $3.5 \mathrm{~kg}$ $(4.7 \%)$ respectively. Acute weight loss methods employed by the lightweight rowers to "make weight" incorporated a combination of several weight loss techniques including the implementation of training rows by $73 \%$ of the participants, fluid restrictions by $71 \%$, sweat runs by $30 \%$, sitting in the car in the sun by $30 \%$, hot showers by $16.5 \%$, sauna by $10 \%$, and heater by $7 \%$. No lightweight rowers reported using pathogenic weight loss techniques.

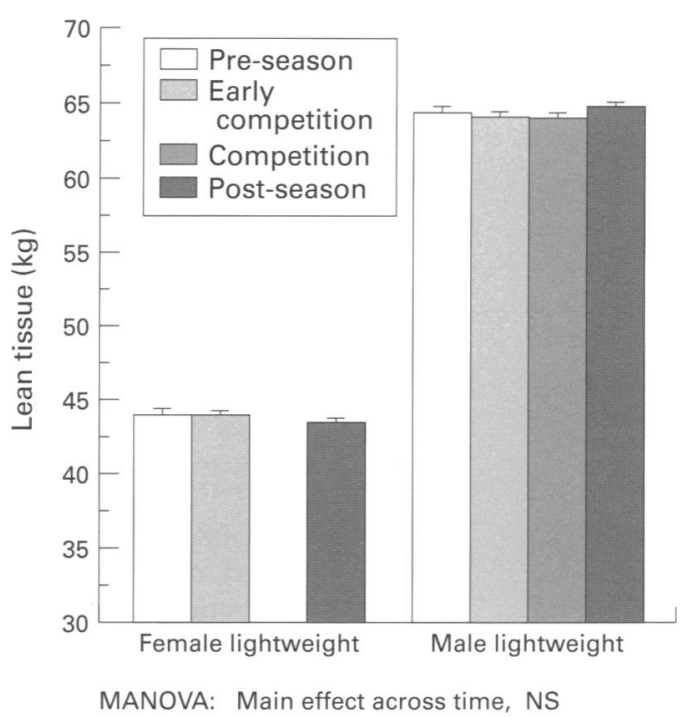

Figure 3 Seasonal comparison of total lean tissue of female $(n=6)$ and male $(n=12)$ lightweight rowers, as measured by dual energy $x$ ray absorptiometry $(D X A)$. Values are means $(\mathrm{kg})$, error bars $=S E M$.

Body weight loss during the competition season corresponded to significant decrease in body fat loss, as estimated by sum of skinfolds, percent fat (table 2), and total body fat $(1.6 \mathrm{~kg}$ female, $1.7 \mathrm{~kg}$ male) (DXA) (fig 2). Postseason, the female and male lightweight rowers showed a significant increase in body fat levels as estimated by all methods.

In contrast to fat mass, the lightweight rower's fat-free mass (FFM) showed no change throughout the season, indicating that weight loss over the season was attributed to reduced body fat (fig 3 ).

\section{Discussion}

Body composition is a critical issue for the lightweight rower, whose goal is to maximise relative power output by increasing lean tissue while minimising total body fat. Both the female and male lightweight rowers recorded a significant body weight loss over the season, losing body weight in order to be eligible to compete. The reduced body weight was regained by the time of the off-season. Our findings were typical of those reported for other lightweight rowers. ${ }^{2}$ McCargar et al ${ }^{2}$ tracked 16 female collegiate lightweight rowers throughout a rowing season and noted a $4.2 \mathrm{~kg}$ weight loss during the competition season, which was subsequently regained during offseason.

The seasonal weight loss was also accompanied by rapid body weight loss by the rowers in the days leading up to race day. During the final week leading up to the regatta, the lightweight rowers were required to lose $4.7 \%$ of their body weight. Concern arises as to the high incidence of temporary and rapid changes used by the lightweight rowers, in preference to a more permanent and gradual weight reduction. This raises the issue of an athlete's natural weight, the weight that the athlete maintains during the off-season. Rowers who naturally weigh at or below the FISA weight limit have no need to employ temporary, medically inadvisable weight loss techniques. Problems may 
arise, however, when the rower has to shed excessive weight from their preseason body weight before being eligible to compete at regattas.

The body weight changes achieved by the lightweight rowers over the course of the season were associated with a corresponding decrease in body fat, with the reduction in body fat being relatively greater in the male lightweight rowers. These body fat alterations in the lightweight rowers are consistent with studies monitoring gender specific seasonal changes in the body composition of athletes. ${ }^{11} 12$ Male distance runners showed greater body fat reductions than female runners and gained more lean mass in response to a 20 week endurance training programme. ${ }^{14}$ Functional studies to explain why females show a more conservative response to exercise induced decreases in energy stores compared to men concluded that the female preservation mechanism of body fat levels is more responsive, as their reproductive function is more readily threatened by changes in energy stores, ${ }^{14}$ that the female response to exercise induced lipolysis stimulation is less, ${ }^{13}$ and that abdominal fat cells in males are more sensitive to stimulation than the adipose tissue in the gluteal-femoral region in women. ${ }^{11}$

Fat-free mass of the lightweight rowers was maintained throughout the season, despite body weight loss from preseason to competition season. However, no increase in FFM was reported, despite engagement in an intensive rowing training programme. The failure to increase FFM was in contrast to the findings in athletes not bound by weight restrictions, where lean mass increases in response to weight training and training. Wilmore ${ }^{15}$ monitored the effect of a 10 week weight training programme and found no change in body weight, but a substantial increase in lean body weight and a corresponding decrease in body fat $(10 \%$ and $7.6 \%$ in females and males respectively), as assessed by hydrostatic weighing. Theoretically, it would be advantageous for the lightweight rowers to lose body fat and increase lean tissue mass, since lean mass has been highly correlated with strength and power output ${ }^{16}$ which is conducive to superior rowing performance. ${ }^{17}$ It is possible that the restricted energy intake, although sufficient to maintain FFM, may be inhibiting the necessary protein synthesis required for muscle growth during the season. ${ }^{18}$

Our results showing a preservation of FFM in the lightweight rowers are in contrast to the findings reported by Koutedakis et al, ${ }^{19}$ who observed a similar body weight loss in elite lightweight rowers across the season, but attributed $50 \%$ of the body weight loss to FFM loss. The discrepancy in findings was possibly attributable to the fact that the female lightweight rowers in the present study had a higher percentage body fat preseason $(22.1 \%)$ compared to the female lightweight rowers in the other study $(14.3 \%)$, indicating our female rowers had more body fat available to lose. During competition season, rowers in the present studv reduced their bodv fat percent- age to $19.6 \%$, whereas the rowers in the study by Koutedakis reached $12.2 \%$, a level which is very close to the proposed minimum body fat levels for females.

\section{CONCLUSIONS}

Lightweight rowers showed seasonal body weight reduction in response to the need to achieve race weight. Longer term body weight reductions were achieved through dietary restrictions and exercise, with food and fluid restrictions and exercise employed only in the seven days leading up to a major regatta. Competition body weight reductions were achieved predominantly in the form of fat mass loss, while preserving FFM. The preservation of FFM, however, may only be possible in the lightweight rowers who have a relatively high percentage body fat at the beginning of the season.

This research was funded by the Australian Sports Commission. We extend sincere gratitude to the Mercy Private Hospital-Radiography Department for their assistance with the DXA scans. Also, appreciation is extended to the Victorian Institute of Sport for their support during the project; and to the coaches and members of the Victorian lightweight rowing team for their cooperation and support.

1 Secher NH. The physiology of rowing. $f$ Sports Sci 1983;1:23-53.

2 McCargar LJ, Simmons, Craton, Taunton JE, Birmingham CL. Physiological effects of weight cycling in female lightweight rowers. Can f App Phys 1993;18:291- 303.

3 Steen SN, Brownell KD. Patterns of weight loss and regain in wrestlers: has the tradition changed? Med Sci Sports Exerc 1990;22:762-8.

4 Burge C, Carey M, Payne W. Rowing performance, fluid balance and metabolic function following dehydration and rehydration. Med Sci Sports Exerc 1993;25:1358- 64

5 Zuti WB, Golding LA. Effects of diet and exercise on body composition in adult women during weight reduction. [abstr] Med Sci Sports Exerc 1973;15:62.

6 Crews E, Fuge K, Oscai L, Holloszy J, Shank R. Weight, food intake and body composition: effects of exercise and of protein deficiency. Am $\mathcal{F}$ Physiol 1960;216:359-63.

7 Withers R, Graig N, Bourdon P, Norton K. Relative body fat and anthropometric predictions of body density of male athletes. Eur $\mathcal{F}$ App Physiol 1987;56:191-200.

8 Withers R, Norton K, Graig N, Hartland M, Venables W. Relative body fat and anthropometric prediction of body density of South Australian females aged 17-35 years. Eur f App Physiol 1987;56:181-90.

9 Siri WE. Body composition from fluid spaces and density: analysis of methods. In: Brozek J, Henschel A, eds. Techniques for measuring body composition. Washington, DC: National Academy of Sciences National Research Council, 1961:223-4.

10 Mazess RB, Barden H, Bisek J, Hansen J. Dual energy X-ray absorptiometry for total body and regional bone minera and soft tissue composition. Am f Clin Nutr 1990;51: 1106-12.

11 Depres J, Bouchard C, Savarde R, Tremblay A, Marcott M, Theriault G. The effect of a 20 -week endurance training programme on adipose tissue morphology and lipolysis in men and women. Metabolism 1984;33:235-9.

12 Tremblay A, Despres JP, Leblanc C, Bouchard C. Sex dimorphism in fat loss in response to exercise-training. $\mathcal{F}$ Obesity Weight Regul 1984;3:193-203.

13 Leibel RL, Hirsch J, Berry E, Green RK. Alterations in adipocyte free fatty acid reesterification associated with obesity and weight reduction in man. Am $\mathcal{F}$ Clin Nutr 1985;42: 198-206.

14 Bjorntorp P. Sex differences in the regulation of energy balance with exercise. Am $\mathcal{F}$ Clin Nutr 1989;49:958-61.

15 Wilmore J. Alterations in strength, body composition and Wilmore J. Alterations in strength, body composition and anthropometric measurements consequent to a 10 week
weight training program. Med Sci Sports Exerc 1984;6:1338 .

16 Mayhew JL, Piper FC, Ware MS. Anthropometry correlates with strength performance among resistance trained athletes. $\mathcal{F}$ Sports Med Phys Fitness 1993;33:159-65.

17 Secher NH. Physiology and biomechanical analysis of rowing. Implications for training. Sports Med 1993;15:24-42.

18 Lemon PWR. Nutrition for muscular development of youn athletes. In: Gisolfi CV, Lamb DR, eds. Youth, exercise and sport. Benchmark Press, 1989:377-86.

19 Koutedakis Y, Pacy PJ, Quevedo RM, Millward DJ, Hesp R Boreham C, et al. The effects of two different periods of weight-reduction on selected performance parameters in elite lightweight oarswomen. Int. 7 Sports Med 1994;15:472-7. 